Journal of Language \& Translation 9-1

March 2008, 61-90

\title{
The Structure and Texture of English Translations of Yorùbá and Igbo Proverbs
}

\author{
Mufutau Temitayo Lamidi \\ University of Ibadan
}

\begin{abstract}
Every culture has its rules of interaction and interpretation, and each also has rules for proverb construction and usage. As a literary genre, proverbs in Yorùbá and Igbo do possess some features that identify them in their areas of usage. These we explore in this paper with particular emphasis on the structure and the texture that proverbs share in the two languages. With data collected from literary works and scholarly publications of Yorùbá and Igbo scholars, this study reveals that proverbs in the two languages have identical structure and texture with few optional items on both sides. This study concludes that proverbs probably have universal structures and textures as found in the two cultures.
\end{abstract}

Keywords: proverbs, intertextuality, genre, Igbo, Yorùbá, structure, texture

\section{Introduction}

The proverb is a witty saying that captures the logic, culture and observations of a people. It often evolves from traditional lore, 
62 The Structure and Texture of English Translations of Yorùbá and Igbo Proverbs

history, and religion, and is usually attributed to elders as it is believed to contain the wisdom of the elders or ancestors in the society (Olatunji 1984). It is considered 'one of the longest surviving non-material artefacts of a heritage' (Nwachukwu-Agbada 2002: 3). The proverb may also be a summary of aspects or the whole theme being put across. It is succinct and pungent, used to add grandeur to an otherwise ordinary speech. Sometimes, it is beyond comprehension to younger people, and elders who are coming across one for the first time often take their cues from the context or ask pointedly or politely what the speaker means by the expression.

In the context of speaking, the proverb is used to capture the totality of an experience such as warning, advice, rebuke, etc. which suits the occasion of discourse. This is probably why it is described as "a lexical element...which is learned as and reused as a single unit with frozen internal structure” (Cram 1994: 75). This means that the proverb recurs with almost the same structure and sense or meaning in different situations where it is used. If this is correct, we may then refer to a proverb text as a phraseme; that is, a unit that is coherent and cohesive, able to stand independently and be meaningful without recourse to another text. In this vein, this paper explores the internal structure of the proverb in Yorùbá and Igbo languages with a view to ascertaining general linguistic and literary features that make it unique as a genre. In the following sections, we discuss the proverb as a text; and explore its contexts and its intertextuality within the African cultural environment.

\section{Data Collection}

Although there are a lot of proverbs written in Yorùbá and Igbo languages, we have decided to use translations of the proverbs in this study. This becomes necessary to avail readers from other 
cultures the opportunity of getting a direct translation of a proverb. This makes it easy to appreciate the similarities and differences in texts. In addition, an $\mathrm{L}_{1}$ speaker of a language has an edge over an $\mathrm{L}_{2}$ speaker in matters relating to the exact meaning of a proverb. Thus translations by the native speakers of the two languages are expected to be close to near perfect.

Hence, 60 proverbs (in original English translations) were extracted from four plays and a classic novel written by scholars with Yorùbá or Igbo linguistic and cultural backgrounds. These plays are Death and the King's Horseman (henceforth Horseman) by Wole Soyinka, The Gods are not to Blame (henceforth The gods) by Ola Rotimi , The State Visit by Niyi Osundare (all written by Yoruba scholars) and Three Plays by J. P. Clark. The novel is Things Fall Apart (henceforth TFA) by Chinua Achebe.(Both Clark and Achebe are Igbo). These were complemented by an additional 60 translated proverbs randomly selected from data provided in Bamgbose (1968), Olatunji (1984) (Yoruba) and Nwachukwu-Agbada (2002) (Igbo).

\section{The Text and Context of Proverbs}

A text can be described as a coherent and cohesive discourse. Whether written or oral, it may be described in terms of semantics, syntax and pragmatics. Hence, Halliday and Hasan (1989:17) define it as a functional language; that is, a language that is performing some functions in a particular text. Following Halliday and Hasan, we can identify the three features of texts in proverbs. As a semantic unit, the proverb text has meaning that can be interpreted within the context of situation; as a syntactic unit, it follows acceptable grammatical norms; and as a pragmatic text, it has wider interpretations that go beyond the ordinary, (especially when used in an ongoing event); and finally, as a literary text, it has literary 
features such as figures of speech, word play and parallelism (Bamgbose, 1968; Olatunji, 1984).

The text is also perceived as a product and a process. As a product, the proverb can be recorded and studied systematically. As a process, it involves a network of meaning potential from which choices are made depending on the environment/situation of use. Proverbs are handed down from a generation to another and when used in a particular context, they contribute meanings.

Finally, the text is a form of social exchange especially dealing with interactions between speakers. This means that meaningful texts are created in interactions (or dialogues). In Africa, proverbs are used in interactions to spice a speech and achieve greater pungency and word economy. It is a unified text which has its own subject matter, participants and events. In all these occurrences, the emphasis is on the context of situation: the context makes the meaning of a proverb come to life. So what is the context of a proverb?

Context is defined in different ways depending on the form in question. Three forms of context have been identified in the literature. These are the context of culture, the context of situation and the context of text. The context of culture is

a large and complex knowledge system spread between various members of a particular culture, and hence consisting of many sets of knowledges, including in particular, the institutional and the ideological... [In] a particular context of situation, the context of culture is accessed by means of the knowledge systems which the various participants bring to bear on the situation, where the knowledge is triggered by aspects of the context of situation” (Leckie-Tarry 1995:20).

This means that the shared knowledge of ideas, participants and events forms the background to the realisation of the meanings in a 
particular text. When taken out of context, the possibility of wrong or meaningless interpretations of texts obtains (Mey 2000).

The proverbs under study are shared by speakers of either Yorùbá or Igbo, who form a speech community - sharing the same language and the same norms of interaction and interpretation (Hudson1996: 27). Thus a proverb is a communal property which individuals use at will, provided they are competent in its usage.

The context of situation is the environment in which the proverb becomes meaningful. Halliday \& Hasan (1989) identify the three categories of field, mode and tenor, which are said to be realized by three metafunctions - ideational, interpersonal and textual (23). The ideational knowledge, being knowledge resources of a culture, refers to the background knowledge within the society. It is gained through experience or from existing texts in a culture. The interpersonal knowledge deals with how people interact in particular situations, especially dealing with participant roles acceptable to the society/culture. Textual knowledge is that gained from other texts including knowledge of intratextual and intertextual contexts. This involves conventions for the realizations and cohesion of texts.

The context of text is the independent realization of meaning within the proverb. This means that the proverb is independent and bears a specific interpretation. However, meanings in a proverb can be analogous to happenings in the real world; and that is why they are invoked at such events.

Since the proverb is based on the wisdom, culture, experiences, history, etc of its society, it is easily interpretable within the society. The proverb is also used in interpersonal discourse by both the young and the old in appropriate contexts. As a text, it is passed down orally but with dialectal variations in some instances. It is used to sum up ideas in a speech event or draw analogies between events/personalities described in proverbs and events. Hence it is a record of past events which are relevant to the contemporary world. Thus we can say that proverbs are texts. If this is correct, then the 
66 The Structure and Texture of English Translations of Yorùbá and Igbo Proverbs

proverb is unique. As a text, therefore, it must have structure and texture. These, we pursue in Yorùbá and Igbo proverbs in the following sections.

\section{The Intertextuality of Proverbs}

Intertextuality refers to part of the environment of a text that originated from a set of previous texts; texts that are taken for granted as shared among those taking part (Halliday \& Hasan 1989: 47). The proverb is said to originate from experiences, historic events, fables, jokes and folktales especially in Armanian (Sakayan 1999: 306) and more especially in Yorùbá (Olatunji 1984). The fact is that native speakers do not ponder over a proverb to know what story or experiences brought it about. (Yoruba has a history of storytelling and other sources of folklore which are commonplace in the society.) What matters is the appropriateness of the proverb. However, the fact remains that the proverb itself has its own topic, participants, channel, theme, events etc (following Hymes’ precepts on ethnography of communication) that brought it into being. Such features above make it a text. However, when it is being invoked in similar situations such that it explains, summarizes, or clarifies ongoing events; or serves as an analogy or metaphor for an event, then the principle of intertextuality is invoked. These events, the real and the proverbial, are two separate texts that are related by theme.

Consider the following example which demonstrates the intertextuality of proverbs; the culture that produced the proverb is specified after each proverb.

(1) One learns to do without the masks he can no longer wear. (Three Plays 7; Igbo) 
(2) The trouser inherits the waist.

The son succeeds the father. (Bamgbose 1968: 79; Yoruba)

(3) One cult member supports (the elbow) of another.

If one cult member does not support (the elbow of) another, The cult will be disgraced. (Bamgbose 1968: 81; Yoruba)

In the first proverb, when a mask becomes useless, the owner has to adjust to not wearing it or possibly repair it. In the second trousers is considered the property of (always used by) buttocks; thus by analogy a son (and no one else) should inherit his father. In the third proverb there are two participants, both cult members. One of them is being encouraged to assist the other so that the cult would not come to disrepute as a result of the other person's failings and the possible loss of face in the process. The import of the proverbs therefore is that happenings in the current situation of speaking should conform to what had happened in the proverb world. Thus the proverbs are expected to be used when situations similar (literally, analogically or metaphorically) to that in the proverb obtain in the society.

As related texts, the stories in the proverbs and the events that called for their use in the society have one theme in common: this is the fact that in (2) a son is the right successor to a father and in (3) one should help a colleague in order to save the face of a group to which both belong. Therefore, the relatedness of the texts in the proverb world and events in the real world can be accounted for under intertextuality. This mutual relationship can be represented in the following figure: 


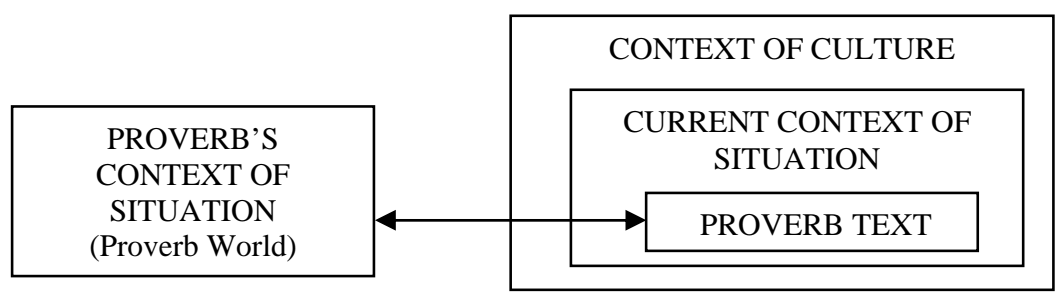

Figure 1: Intertextuality of Proverbs

The proverb's context of situation in the left hand of the diagram subsumes the original field, mode, and tenor which occurred at the time the proverb was being made. It refers to the situation that makes the proverb meaningful as a text independent of the environment in which it is now used. On the right hand side is the current context of situation that triggered the invocation of the proverb. What this means then is that the similarity in the context of situation (they obviously have the same context of culture as they are readily interpretable within the cultural environment) makes the texts similar. They differ, however, in terms of participants. The participants in the proverb are only analogous to the participants in the current speech event. Thus we can see that the texts of the proverbs under study share certain features with the events in which the proverbs are used.

\section{The Proverb as a Unit of Discourse}

The proverb is defined as "a lexical element with a quotational status ... in the sense that it is a syntactic string which is learned and reused as a single unit with frozen internal structure" (Cram 1994: 75). By this definition Cram means that the proverb is an indivisible whole expression. This view probably derives from the ability of a proverb to recur with constant meaning whenever it is invoked. This makes the proverb text unique. Nevertheless, contrary to Cram's 
claim above, the proverb is subject to variations which are largely structural (grammatical, phonological and stylistic),

A proverb is unique to the extent that it has one underlying meaning. Within the Transformational Generative Grammar, the distinction between a deep structure and a surface structure is enunciated. The deep structure has the basic meaning while the surface structure can have various structural arrangements. This is analogous to the distinction between semantic deep structure and surface structure. Really, what this means is that a proverb might be couched in different words, the meaning still remains the same. Hence despite its dialectal or generational variations the proverb still maintains its uniqueness as a text. Note however, that this kind of proverb differs from the postproverbials (Raji-Oyelade 2004) in that they have not undergone deconstruction. Hence they can be described as the traditional text (as opposed to the postproverbials that are of relatively modern origin).

The proverb has been compared with idioms (Cram 1994), and it seems to share the same values with slogans. All are unique, being individual expressions whose meanings may not necessarily be realised at the surface level. The three items (proverb, idiom and slogan) share similar features. First, they do not change their meanings, because each occurs with similar meanings wherever it is used. Second, they sum up ideas (which may or may not have been presented earlier). Third, they do not allow their constituents to be substituted anyhow; i.e. the words and their categories are relatively fixed though they can be twisted through a user's creative ability. Hence they could be described as phrasemes i.e. expressions that recur with constant meaning with little or no change to its components. These descriptions tally with those of the proverbs under study. 
70 The Structure and Texture of English Translations of Yorùbá and Igbo Proverbs

\section{The Structure of Proverbs: Contextual Configuration}

Halliday \& Hasan (1989) have observed that a text has both structure and texture. Given our discussions on the textual nature of Yorùbá and Igbo proverbs above, we shall discuss the structure of the proverbs in this section. The proverb structure can be discussed at two levels. The first, the macro level, is the structure of the proverb as part of a speech event; the second is the structure of the proverb as an entity independent of other texts.

\subsection{The Structure of a Proverb within a Speech Event}

It has been observed that the proverb is usually invoked or cited (Cram 1994: 75) during speech. This is because proverbs are often used to spice a speech, summarize ideas during discussions, draw analogies, etc. The fact is that proverbs in both cultures (and even other cultures) are not said in abstraction, they accompany statements (or vice versa) in speech events. The speech event includes the speaker and the audience. The audience may be parentteacher's association meeting, a religious congregation, a political rally, traditional court proceedings, etc. The number in these audiences may be large or small. The fact is that an audience is necessary for a proverb invocation.

In speech events, Yorùbá and Igbo proverbs are usually culturally and traditionally credited to elders. However, such 'elders' are hardly identifiable because those that ought to be considered as elders often use the reportorial style as in (4-6). This is possibly due to humility on the part of the speaker as the societies frown at arrogance especially before elders. In using a proverb, therefore, certain introductory statements/expressions which show honor to the elders may precede it as in the following: 
(4) The elders of my tribe have a proverb: 'because the farmowner is slow to catch the thief, the thief calls the farmowner thief'. (The gods 46)

(5) Well, our elders have said it: Dada may be weak but he has a younger sibling who is truly fearless. (Horseman 40)

(6) Our elders say that the sun will shine on those who stand before it shines on those who kneel under them. (TFA 5)

These are instances of invoking the imaginary elders who are assumed to be custodians of the society's tradition. Such expressions (printed in bold) are meant to pay homage to the elders in the society and thus telling a proverb is often attributed to the elders. Sakayan (1999) observes that Armenian proverbs are usually credited to elders because the unlettered speaker wants to sound more credible. In Igbo, proverbs are used to confer authority on a person's viewpoint (Nwachuku-Agbada 2002: 5). In Yorùbá, this may not be so. The major reason is that of showing humility to elders (Olatunji, 1984: 171).

Apart from elders, the source may be attributed to the race which is just like referring to the elders or the ancestors.

(7) The Igbo say that when the moon is in the sky, the lame man becomes hungry for a walk. (Nwachukwu-Agbada (2002: 88; Igbo)

Really, the import is the same: that of showing humility before the audience. Nevertheless, Nwachukwu-Agbada (119) observes that proverbs may be attributed to madmen, clowns and never-do-wells for purposes of humor. This is not the case in Yorùbá.

The proverb which begins with an invocation of elders' authority often encourages the audience to respond. Thus, in Yorùbá tradition, 
72 The Structure and Texture of English Translations of Yorùbá and Igbo Proverbs

the audience is expected to answer as follows o ó pa òmíràn 'you will say another proverb i.e. 'May you (live long to) say more proverbs'. In Igbo, there seems to be no such reply; but there may be responses in form of back channel behavior, as in the following proverb.

(8) Protect your female children from irresponsible visitors who want to turn the school to a brothel but for my watchful care. But there is a limit to what one person's eyes can do. Do I know what is happening when I am asleep? The monkey says he (sic) only knows what the child she is carrying in her stomach is doing, not the one on her back.(laughter) ... I can see his royal Highness seated there. Does anybody struggle for kingship? (No! replies the audience). I can see at least five ozo title holders here. If a secret decision is taken behind a great man (the audience completes the saying). (Nwachukwu-Agbada 2002: 65-66; Igbo)

In this excerpt, the proverbs are typed in italics. In the first proverb, the audience laughed; in the second, the audience said No and in the third, they completed the proverb for the speaker. It follows then that audiences of Igbo proverbs can also respond to its use.

The proverb, whether in Yorùbá or Igbo culture, may occur anywhere in the discourse. The choice is left to the user to put it (or them) where it (they) will be very effective. Thus, proverbs can occur at the beginning, middle and end of discourse. In addition, multiple proverbs may be used consecutively to stress a point and interactants may use proverbs to exchange ideas. In some cases, however, this may be temporary as speakers may revert to ordinary words after a while as found in this dialogue between two Yorùbá adolescents one of whom had been cheated (pseudonyms are used for the speakers' names): 
(9) Taiwo: growing up affords one the opportunity of cheating the young ones.

Kehinde: Well, today's children are tomorrow's elders. (Yoruba)

This shows that contrary to Daramola's (2004: 28) opinion, the young ones in Yorùbá do use proverbs, and they are proficient at it too. Children also use proverbs in Igbo. However, as a sign of respect, they may not exchange proverbs when they interact with people older than them (elders). (Nwachukwu-Agbada 2002: 47).

Given the foregoing, we realize that both Igbo and Yorùbá have some affinity in terms of the organizational structure of proverbs. Thus the structure of proverbs in either culture may follow the following pattern:

Opening : Honorifics to elders, race or society

Body : The proverb or proverbs

Closing: Response from the audience

In this order, the opening and the closing are optional depending on the context of speaking. In Yorùbá, the order may be changed such that the honorific statement comes after the proverb. This form is used either for stylistic reasons or possibly when speakers forget to acknowledge the elders before they say their proverbs as in (10).

(10) I seek your pardon/My respects; I am too young to say a proverb before you/I should not say a proverb when you are seated. (Yoruba)

In this case, the audience's response follows the honorific statement. Notice that this occurs in different settings such as discussions/ speeches at family meetings, king's palace, social ceremonies (weddings, funerals) and so on. 
74 The Structure and Texture of English Translations of Yorùbá and Igbo Proverbs

\subsection{The Unified Structure of Yorùbá and Igbo Proverbs}

Having looked at the proverb structure in the two languages from a macro level, we shall now explore the structure at a micro level. In the following discussions, we present data from the two languages and offer explanations/interpretations of the proverbs.

\subsubsection{Proverbs are Context-based}

Proverbs are often society based. They are said as part of a person's speech in a particular context. This context can be defined as the situation or event that provoked the invocation of a proverb. A proverb must conform to the society's norms of interpretation and interaction. This in essence means that it must be interpretable within the context in which it occurs. It does not matter what the event is, a speaker can say a proverb that is relevant to that event; and a listener should be able to interpret it within the social event in which it is used. Thus a proverb may not be said in the abstract sense or without any reference to a specific context. This context must include topic, participants, setting and subject matter (cf., Hymes 1962). The proverbs in Yorùbá and Igbo conform to these 'rules'. Each is interpretable within its cultural environment. As we noted above, they are used by individuals especially elders; and to show respect, they attribute the source of the proverbs to elders or the race. Let us explore some of Hymes' ethnography of speaking vis-à-vis proverb usage in Yorùbá and Igbo languages.

First, proverbs in the two cultures can be used on any topic and every situation of human endeavor. The only caveat is that specific proverbs must match specific occasions. Otherwise, they might be twisted to suit certain occasions especially when one tries to avoid giving offence as observed by Nwachukwu-Agbada (2002: 68) 
(11) Well, if a woman cannot...if a medicine man cannot afford prosperity, let him at least have a big tummy (Igbo)

In this proverb, Nwachukwu-Agbada observes, the speaker had wanted to use a proverb that says if a woman cannot have a child, let her look at least healthy; But he had had to change the proverb so as not to give offence to his friend's wife who had been barren.

Another aspect of Hymes' features is participant. This will be seen in two perspectives. First is the concept of participants of the proverb; i.e. the people who say proverbs and their audiences. The second is the people or things in the proverb. The participants are the entities mentioned in the proverb. Such include animate and inanimate nouns, human and non-human nouns. However, such participants must have the ability to perform an action, though it need not perform that action in the proverb (it may be attributed to it). It follows then that the participant in a proverb may be active or passive. Consider the following

(12) Where the storm pleases, and when, it directs the giant of the forest. (Horseman 14; Yoruba)

(13) The monkey and gorilla may claim oneness but the monkey is Monkey, the gorilla, Gorilla. (The gods 51; Yoruba)

(14) How many, oh how many shall we count of the teeth of Adepele.

There are twenty incisors, fifty canines, while uncountable molars lie buried In the canvas of the jaw (State Visit 9-10; Yoruba)

(15) The ram does not cry out for help although it is led into captivity. (Three Plays 12; Igbo) 
76 The Structure and Texture of English Translations of Yorùbá and Igbo Proverbs

In all these examples, certain participants such as storm, monkey and gorilla are active; participants while forest, Adepele, molars, ram and canines are passive. This is possibly because they occur in passive constructions or they are things being talked about.

When actions occur, they take place in a particular environment. We noted above that proverbs are used at different places and in particular situations. The proverbs cannot be used without any speech event. The proverb can be written or spoken; covering any topic or subject matter.

\subsubsection{Proverbs Sum Up a Speaker's Idea}

Following the discussions above, it is axiomatic that the proverbs must be related to a current event. Of course, it can draw relevance from past events; the proverb is relevant to an ongoing speech. Otherwise, it would not be necessary to invoke it for current speech. For current event, it states or summarizes in a nutshell an idea that would have been expressed in several words. Proverbs in the two languages are often apt such that they provide a deeper understanding of a message mores than ordinary words can do.

\subsubsection{Proverbs May Contain Figures of Speech}

Perhaps one main feature that ensures speakers' interest in proverb usage is its use of literary aesthetics. These occur regularly in Yorùbá and Igbo proverbs which contain extensive use of figures of speech. These include metaphors, personification, rhetorical question, analogy, etc. Some of them are as follows.

Since the proverb is a co-text, it is often woven round a particular theme, concept or idea which has resemblance with the events in which the proverb is used. Thus a proverb thrives on analogy. For instance consider the following proverbs: 
(16) When the evil-plotter beats his drum for the downfall of the innocent, the gods will not let that drum sound! (The gods; Yoruba)

(17) The lizard that jumps from the high iroko tree to the ground said he would praise himself if no one else did.(TFA 15-16; Igbo)

(18) It is like Dimaragana who would not lend his knife for cutting up dog meat because the dog was taboo to him, but offered to use his teeth.(TFA 48; Igbo)

In the first proverb, there is a theme of enmity and this occurs between the proverb user (King Odewale) and his interlocutor (Aderopo). This same theme occurs between the 'evil-plotter' here and the 'innocent'. Thus we can infer that Odewale is the innocent party while Aderopo is the evil-plotter that beats the drum. In the second proverb, the analogy is with a lizard. The subject of discussion, Okonkwo, is compared to a lizard that performs a great feat of jumping down from a tall iroko tree. In the third example, the practice of Ozo title holders where they are forbidden from tapping from tall palm trees but allowed to tap short ones is being criticized. In essence, the themes of the proverbs and the situations of use rhyme in both cultures.

The metaphor is a direct assertion that shows comparison with an entity/referent. It "involves parts of a text being used to refer not to their conventional referents, but unconventionally to other objects or concepts” (Goatly 1993:113). Goatly observes that a metaphor can be grammatical or lexical. These classifications are not relevant to proverbs since the latter are texts that are larger than grammatical constructs. However, it can also be simple, compound, mixed, extended or dead.

A simple metaphor can be in form of a word, phrase or simple 
78 The Structure and Texture of English Translations of Yorùbá and Igbo Proverbs

sentence. In the following proverbs, which are metaphors, the simple sentences are exemplified. However, we found no examples of lexical or phrasal metaphors in the works selected for data collection.

(19) The horns cannot be too heavy for the head that must bear them.(The gods 21; Yoruba)

(20) But money says: "let nobody make any plans without me.” (State Visit 14; Yoruba)

(21) Proverbs are the palm oil with which words are eaten. (TFA 15; Igbo)

The extended metaphor is described as a form which has a principal subject and additional subjects or comparisons. Consider the following proverbs:

(22) It is the death of war that kills the valiant.

Death of water is how the swimmer goes. It is the death of market that kills the trader.

And death of indecision takes the idle away . (Horseman 43; Yoruba)

In this proverb, the subject of discussion is death, and this concept is identified in other items in nature.

Metaphors often have tenor and vehicle. The tenor is that to which attributes are attached while the vehicle is the subject of discussion as in the following:

(23) The strictest father unbends his brow when the child is penitent, Elesin. (Horseman 16; Yoruba) 
(24) The elder grimly approaches heaven and you ask him to bear your greetings yonder; do you really think he makes the journey willingly? (Horseman; Yoruba)

In (23), Elesin is compared to a father that is strict. Thus it is the tenor, while the strictest father and his child are the vehicle. In some cases, however, the tenor can only be deduced from the context of speaking, since it may not be mentioned in the proverb. In (24) for instance, Elesin is still the tenor, but this can only be deduced from the interactions of the characters in the play. The proverb exhibits only the vehicle just like any other metaphor.

These are questions which require no answers but are just used to emphasize certain ideas. This is the import of the following proverbs which are couched in rhetorical questions.

(25) When crocodiles eat their own eggs, what will they not do to the flesh of a frog? (The gods 53; Yoruba)

(26) Why should we chase to Sokoto what we have here in the pocket of our Sokoto? (State Visit 19; Yoruba)

(27) Is it not the house rat that informs the bush rat that there is meat in the grilling basket? (Nwachukwu-Agbada 2002: 76; Igbo)

The proverb in (25) reiterates the speaker's convictions that there were intrigues against him, while that in (26) shows the necessity for looking inward for our needs. The last proverb brings up the idea that a betrayer was involved in an incident.

Irony is a figure of speech where the speaker says the direct opposite of what is intended. Such examples also occur in the data for this study. Here are some examples: 
(28) If the woman complains I beat her up because he who kills his medicine man has also rendered his enemies powerless. When she offends me and I call her attention to it, she roars at me like a lioness because a husband enjoys the food offered to him by a rude-voiced wife. (Nwachukwu-Agbada 2002: 83; Igbo)

In this excerpt, the proverbs in italics are twisted to read the opposite of what they mean. The first means that a man that kills his medicine man could not render his enemies powerless (since it is the medicine man that normally protects him). The second is obvious: husbands don't enjoy the food offered by a rude wife. NwachukwuAgbada noted that the proverb user was advising a newly wedded couple on how to live a blissful matrimonial life. Hence, the proverbs mean exactly the opposite of what they say.

In personification, human attributes are invested on non-human referents. This is to make the expressions vivid. It is like saying those participants have certain contributions to make to the discourse even if they are not animate, as in the following:

(29) But money says; 'Let nobody make any plans without me'. (State Visit 14; Yoruba)

(30) The bush-rat fled his rightful cause, reached the market and set up a lamentation. (Horseman 69; Yoruba)

(31) Eneke the bird says that since men have learnt to shoot without missing, he has learnt to fly without perching. (TFA 16; Igbo)

(32) They say the crooked Wood tells the expert carver. (Three Plays 12; Igbo) 
In (29-32), money, bush-rat, bird and wood are personified to draw a comparison between them and a referent in the outside world. Note that in Yorùbá culture, tortoise stories are narrated to children for them to learn some lessons. The same idea seems to be at play here. Amali (1999) notes that stories constitute a source of Idoma proverbs. The same thing can be said of Yorùbá and Igbo proverbs, and these are examples of such.

\subsubsection{Proverbs Contain Patterned Structures}

Bamgbose (1968) and (Nwachukwu-Agbada (2002:140) have respectively observed that Yorùbá and Igbo proverbs can take different shapes such as simple, complex, sequential, and parallel sentences. In translation, the proverbs also follow similar lines. In the following, we offer examples of parallel structures:

(33) It is not changing into the lion that is hard It is getting the tail of a lion. (The gods 7; Yoruba)

(34) It is the death of war that kills the valiant Death of water is how the swimmer dies. (Horseman 43; Yoruba)

(35) A tricky person dies, a tricky person buries him. (Nwachukwu-Agbada (2002:140; Igbo)

(36) A child learns to climb a tree, his mother learns how to cry. (Nwachukwu-Agbada (2002:140; Igbo)

In each pair of the proverbs above, the second clause balances the first and therefore makes its memorization and recollection easy. 
82 The Structure and Texture of English Translations of Yorùbá and Igbo Proverbs

\subsubsection{The Diction is Usually Simple.}

The word choices of proverbs are often simple. This is understandable since the expressions are usually metaphorical or analogical. If the language is difficult or elevated, it might become impenetrable for audiences and the purpose of using the proverb is therefore defeated.

Of all these features, which are optional and which are obligatory? A close look at the examples shows that subject matter (which includes the participant), theme, context, metaphor/analogy, and simple language usage are obligatory features of a proverb. In addition, the proverb must be used in a particular context (situation/event). It is however optional for a proverb to contain figures of speech, be oral or written. It is also optional for a proverb to take on particular forms of metaphor. What matters is that there should be a one-to-one correspondence between a supposed metaphoric usage and an actual event.

\section{The Texture of Yorùbá and Igbo Proverbs}

According to Bloor \& Bloor (1995: 86), “Texture is simply the quality of being a text, rather than a set of unconnected bits of language such as one might find in a collection of independent sentences used as exercises in a text book". The texture as discussed by Halliday \& Hasan (1989) shows the textuality in proverbs; that is, the coherence and cohesion of the proverbs. Many features can be identified as contributing to the texture of proverbs. These include the lexis and their relationship to one another. These we discuss below with their sense relations. 


\subsection{Antonymy}

Antonyms show meaning relation of contrast. In proverbs, words are strategically placed such that the contrast is the major item that brings out the intended meaning of the proverb. Witness the following:

(37) Those that spoil are not scarce.

What is scarce is those that improve. (Olatunji 1984: 179; Yoruba)

(38) He who is ungrateful for an act of kindness Will not feel the pain if he meets unkindness. (Olatunji 1984: 180; Yoruba)

(39) An elder should not be in the market-place and allow the child's head to hang. (Olatunji 1984: 176; Yoruba)

(40) If the wicked prospers and the righteous does not One gets tired of doing good. (Olatunji 1984: 177; Yoruba)

(41) Pecking and pecking wealth vanishes; picking and picking wealth flourishes. (Nwachukwu-Agbada 2002: 167; Igbo)

The antonymous pairs of words italicized in the foregoing examples show meaning relations. Really, the contrast in the meaning ironically highlights the message of each proverb. In (37) spoil and not scarce are contrasted with improve and scarce. In (40) wicked and righteous are contrasted. Hence the meaning relation is that of contrast. 
84 The Structure and Texture of English Translations of Yorùbá and Igbo Proverbs

\subsection{Metonymy}

Metonymy is a relation of part for whole. In this sense, a part of an item is considered as standing for the whole part. Consider the following:

(42) When eyes miss each other's eyes,

Let not the original agreement fail. (Olatunji 1984: 176; Yoruba)

(43) One’s own palms do not deceive one. (Olatunji 1984: 173; Yoruba)

(44) A single hand does not lift a full calabash to the head . (Olatunji 1984: 173; Yoruba)

In these proverbs, eyes, palm and hand stand for individuals that own these parts of the body. Sometimes, they represent the person's efforts. Thus (42) means that each individual (possibly at a meeting) should not deviate from an agreement after they disperse; in (43) palm belongs to the individual who uses it to work and in (44), hand refers to an individual's sole efforts at a task.

\subsection{Co-extension}

Items in this group refer to words that are found in the same meaning area. Witness:

(45) If one does not find a forest bat

One may use a house bat for sacrifice. (Olatunji 1984: 176; Yoruba)

(46) It is today that we know; we don't know tomorrow. 
(Bamgbose 1968: 76; Yoruba)

(47) If the eye sees, the mouth will keep shut. (Bamgbose 1968: 77; Yoruba)

(48) The hawk is playing with the pigeon, (and) the pigeon is flattered; the pigeon is playing with death. (Bamgbose 1968: 81-82; Yoruba)

(49) A man whose thing is all right does not know what a man with hydrocele suffers. (Nwachukwu-Agbada 2002: 177; Igbo)

In (45-49), today and tomorrow, eyes and mouth, hawk and pigeon, thing and hydrocele as well as forest bats and house bats are related through co-extension. Today and tomorrow are days, eyes and mouth usually work together for effective communication; forest bats and house bats are two birdlike animals that are found in different habitats. The relationship is possibly in their physical features. The hawk and the pigeon also belong to the same class of birds, and in the Yorùbá society, they are viewed differently: the hawk steals and kills chicks but the pigeon co-exists with other domestic birds and is playful in the society. All these relationships foreground the interpretation of the proverbs and add to the cohesion/coherence of the text.

\subsection{Collocation}

Collocation is described as the company words keep. In the following examples, the words printed in italics collocate.

(50) If a blacksmith continues to strike an iron at one point alone, there must be a flaw there. (Olatunji 1984: 179; 
86 The Structure and Texture of English Translations of Yorùbá and Igbo Proverbs

Yoruba)

(51) One does not collect fowls without the knowledge of the cage. (Olatunji 1984: 178; Yoruba)

(52) A chic that will grow into a cock can be spotted the very day it hatches. (TFA 46; Igbo)

(53) If a ball of foo-foo is afraid, it asks the vegetable in the soup to accompany it. (Nwachukwu-Agbada 2002: 171; Igbo)

In (50-51) fowls and cage collocate since fowls are often housed (even traditionally) in cages in the Yorùbá society; and blacksmiths work principally using iron or metal. In (52) chic collocates with cock and hatches. And foo-foo collocates with vegetable and soup. The occurrence of these contributes to the meaning.

\subsection{Synonymy}

This is a relation of similarity in meaning between words in a text. Consider the following proverbs:

(54) The person that does evil to others does havoc to himself. (Bamgbose 1968: 76; Yoruba)

(55) The war drum is cryptically beaten like a proverb. It is wise men that dance to it.

It is informed men that know it. (Olatunji 1984: 170; Yoruba)

The pair of words evil and havoc, and wise and informed are near synonyms which contribute to the surprise intended in each of the proverbs. 


\subsection{Discordant Pairs}

Finally in this section, we discuss what may be described as discordant pairs. These are pairs of words that are not antonymous but whose referents are considered not to be at par in the society. The real issue obtains in the sense that one spoils the other or hurts the other. Consider the following:

(56) Wearer of white dress does not sit in a palm oil store. (Olatunji 1984: 178; Yoruba)

(57) He whom one asks to help scrub one's back hides a thorn in his palm.

He whom one asks to blow out the dirt in one's eyes puts some pepper in his mouth.

He whom one asks or decided to confide in is indeed one's betrayer. (Olatunji 1984: 178; Yoruba)

(58) A timid rat says that the cat is watching it. (NwachukwuAgbada. (2002: 171; Igbo)

In these examples, the items printed in italics are pairs which are socially separated because one may spoil/hurt the other. For instance, palm oil may soil a white dress when both come into contact; thorn may hurt one's back if they are used to scrub it; pepper is certainly not a friend to the eye as it will sting the eye; a betrayer is not to be considered a true friend and finally, cat is an enemy to rat. Thus the co-occurrence of the pairs in each line points up the intended meaning of the proverbs. 
88 The Structure and Texture of English Translations of Yorùbá and Igbo Proverbs

\section{Conclusion}

This paper has studied the textual and textural features of proverbs in Yorùbá and Igbo. It reveals that the proverb in the two languages has both micro and macro structures. As a text, the proverb has a texture such that the whole proverb contains words that hang together and make it a phraseme. The paper also discussed the intricacies of meaning relations in proverbs. In speech events the proverb has a distinct structure with a speaker-audience interchange and features such as simple language, figures of speech and literary devices that stand it out as a text and make it comparable to other literary texts. The paper also proposes recognition of the existence of another semantic feature discordant pairs, which plays a role in the cohesion of proverb texts.

Given the foregoing, we can postulate that the proverb in both languages have similar features structurally and texturally. They only differ in the realization of some elements For instance, proverbs may be attributed to madmen, clowns, never-do-wells for purposes of humor in Igbo, but not in Yoruba; Yoruba has specific forms of response to proverbs but Igbo uses back channel behaviour as response. Moreover, examples of metonymy were not found in our data (42-44), probably because the data was limited to a few published works.

Furthermore, we have drawn some similarities with Armenian and Idoma proverbs above. The proverbs studied in this paper were sourced from Igbo and Yoruba, two Nigerian Languages. Igbo belongs to the Igboid group of languages while Yoruba is a Kwa language. Given the disparate nature of languages and the similarities identified in the discussions above, it is possible that proverbs in other languages will have many of the features identified in this paper 


\section{References}

Achebe, C. 1958. Things Fall Apart. Ibadan: Heinemann.

Amali, O. 1999. Sources of Idoma Proverbs: A Guide to Paremiographers. Proverbium 16, 1-21.

Bamgbose, A. 1968. The Form of Yoruba Proverbs. Journal of African Studies 4.2, 74-86.

Clark, P. 1964. Three Plays. Oxford: Oxford University Press.

Cram, D. 1994. The Linguistic Status of the Proverb. In M. Wolfgang (ed.), Wise Words Essays on the Proverb 73-98. New York \& London: Garland Publishing Inc.

Daramola, Y. 2004. Yoruba Proverbs in the Perspective of Music. Proverbium 21, 27-34.

Goatly, A. 1993. Species of Metaphor in Written and Spoken

Varieties. In M. Ghaddessy (ed.), Register Analysis Theory and Practice 110-148. London: Pinter Publishers.

Halliday, K. \& R. Hasan. 1989. Language, Context and Text: Aspects of Language in a Social Perspective. Oxford: Oxford University Press.

Hudson, A. 1996. Sociolinguistics. Cambridge: Cambridge University Press.

Hymes, D. 1962. The Ethnography of Speaking. In T. Gladwin \& W.

Sturtevant (eds.), Anthropology and Human 15-53. Washington

DC: Anthropological Society of Washington.

Leckie-Tarry, H. 1995. Language and Context: A Functional Linguistic Theory of Registe. London: Pinter.

Mey, J. 2000. When Voices Clash a Study in Literary Pragmatics.

New York: Mouton de Gruyter.

Nwachukwu-Agbada, J. 2002. The Igbo Proverbs: A Study of Its

Context Performance and Functions. Enugu: John Jacob's

Classic Publishers Ltd.

Olatunji, O. 1984. Features of Yoruba Oral Poetry. Ibadan: University of Ibadan Press.

Osundare, N. 2002. The State Visit. Ibadan: Kraftgriots. 
90 The Structure and Texture of English Translations of Yorùbá and Igbo Proverbs

Raji-Oyelade, A. 2004. Posing the African Proverb: A Grammar of Yoruba Postproverbials, or Logophagia, Logorrhea and the Grammar of Postproverbials. Proverbium 21, 299-314.

Rotimi, O. 1971 The Gods are Not to Blame. London: Oxford University Press.

Sakayan, D. 1999. Reported and Direct Speech in Proverbs: On Armenian Dialogue Proverbs. Proverbium 16, 303-324.

Soyinka, W. 1975. Death and the King's Horseman. Ibadan: Spectrum. 